\title{
Accuracy of Determination of Self-Diffusion Coefficients in Studies of Porphyrin-Based Complexes by 2D DOSY
}

\author{
Ilya A. Khodov \\ G.A. Krestov Institute of Solution Chemistry, Russian Academy of Science, 153045 Ivanovo, Russia \\ Kazan Federal University, 420008 Kazan, Russia \\ E-mail:iakh@isc-ras.ru
}

\begin{abstract}
Influence of chemical exchange processes on the accuracy of determination of self-diffusion complexes of porphyrinnickel complexes was shown. A method of estimating the inaccuracy of the self-diffusion coefficients for an inverted porphyrin complex was proposed. The values obtained using two different approaches to recording DOSY spectra, STE and CPMG, were compared. Allowing for exchange was shown to be important for accurate diffusion measurements and correct interpretation of results obtained in studied of molecular-level processes.
\end{abstract}

Keywords: NMR, 2D DOSY, self-diffusion coefficients, chemical exchange, $J$-modulation, $N$-confused porphyrins.

\section{Точность определения коэффициентов самодиффузии \\ в исследовании комплексов на основе порфиринов методами 2D DOSY}

\section{И. А. Ходов}

ФГБУН Институт химии растворов им. Г.А. Крестова Российской академии наук, 153045 Иваново, Россия ФГАОУ ВПО Казанский (Приволжский) федеральньй университет, 420000 Казань, Россия

E-mail: iakh@isc-ras.ru

\begin{abstract}
В данной работе было показано влияние обменных прочессов на точность определения коэффициентов самодиффузии никелевого комплекса порфиринов. Был предложен метод оценки погрешности коэффициентов самодиффузии для инвертированного порфиринового комплекса. Был проведен сравнительный анализ коэффициентов самодиффузии для двух различных подходов получения спектров 2D DOSY (STE u CPMG). Показана важность учета обменных прочессов для получения более точных коэффициентов самодиффузии и корректной интерпретации результатов, полученных при исследовании процессов, происходящиих на молекулярном уровне.
\end{abstract}

Ключевые слова: ЯMP, 2D DOSY, коэффициенты самодиффузии, химический обмен, J-модуляция, инвертированные порфирины. 


\section{Introduction}

NMR spectroscopy is widely used in investigations of structure and dynamics of small molecular weight compounds ${ }^{[1-5]}$ as well as of relatively large macrocyclic molecules, ${ }^{[6-11]}$ including porphyrins. ${ }^{[12-15]}$ Modern NMR methods play a special role in studied of formation of intermolecular complexes and associates, ${ }^{[16-18]}$ and in identifying supramolecular assemblies. ${ }^{[19-24]}$ In studies of intermolecular interactions in porphyrin complexes, a number of efficient approaches can be applied, including classical analysis of chemical shifts and relaxation times and modern two-dimensional methods such as nuclear Overhauser effect ${ }^{[25-27]}$ and diffusion-ordered spectroscopy (DOSY). ${ }^{[1,13,28-34]}$ Each of them has its own strong and weak sides. Temperature dependency of the integral intensities of cross-peaks in 2D NOESY spectra can yield reliable information on the molecular interaction in the presence of chemical exchange. However, this approach is rather timeconsuming and does not necessarily give full information on physical-chemical properties and exchange parameters. Another promising approach is analysis of self-diffusion coefficients obtained in DOSY experiments. Today this method is mainly used in qualitative assessment of molecular interaction. Obtaining reliable values which can be used in qualitative analysis is not simple since there are many factors influencing the final result; these are experimental parameters which should be controlled with a high accuracy (sample height, field homogeneity, pulse shape, gas flow rate, etc.) and factors arising from the chemical structure and intramolecular flexibility of characteristic groups of the studied compound.

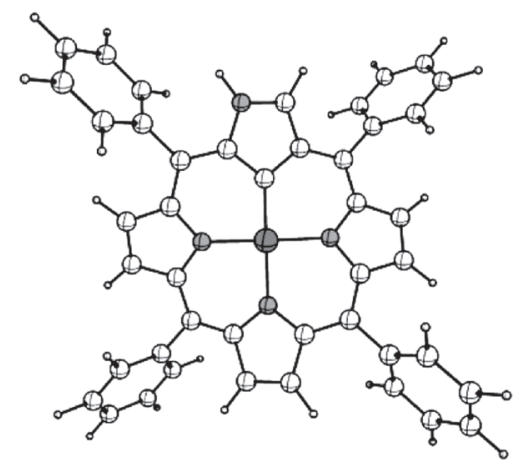

Figure 1. Scheme of the nickel complex of inverted 2-aza5,10,15,20-tetraphenyl-21-carboporhyrin.

In this paper we analyze two different approaches in NMR spectroscopy for measuring self-diffusion coefficients on the example of well-known inverse nickel-porphyrin complexes (Figure 1). ${ }^{[35-40]}$ The choice of the object is justified by an observation that dimers often appear in synthesis of these compounds. ${ }^{[41,42]}$ Information on complex formation and on its existence in monomeric or dimeric form is thus important. Furthermore, some of the metal-porphyrin complexes are unstable, and kinetic studies of self-diffusion coefficients can shed light on possible dissociation pathways of these complexes.

\section{Experimental}

Synthesis of the studied nickel complex was described earlier. ${ }^{[35,43-46]}$ Its chemical structure was proved by ${ }^{1} \mathrm{H}$ NMR spectroscopy, 2D DOSY and 2D COSY spectra. ${ }^{[42]} \mathrm{NMR}$ measurements were carried out on a Bruker Avance III 500 instrument using a standard $5 \mathrm{~mm}$ probehead and TopSpin software. Temperature control was achieved using a BVT-2000 unit and a BCU-05 chiller. Experiments were performed at $303 \mathrm{~K}$ without sample spinning. Deuterated $\mathrm{CDCl}_{3}$ from Sigma Aldrich was used for sample preparation.

Two-dimensional diffusion-ordered spectroscopy experiments were conducted using two different methods. The first is based on the stimulated echo pulse sequence (STE) with bipolar field gradient pulse and additional delays (LED), and the second is based on the Carr-Purcell-Meiboom-Gill sequence (CPMG). Other experiment parameters were the same: diffusion delay of $0.1 \mathrm{~s}(\Delta)$, 64 scans per increment, 16384 complex points in the F2 dimension, the ramp consisted of 32 gradient amplitudes.

\section{Results and Discussion}

The DOSY method is readily applied to systems in which there are no exchange processes. Otherwise, problems arise which influence the accuracy of determination of selfdiffusion coefficients. ${ }^{[47]}$ This is due to the fact that most of modern DOSY pulse sequences (such as Oneshot45) ${ }^{[48,49]}$ employ stimulated echo (STE) elements. Its goal is to eliminate Foucault currents and effects of $J$-modulation. Magnetisation transfer occurring during the STE period due to either chemical exchange ${ }^{[50,51]}$ of $\mathrm{NOE}^{[52]}$ influences the resulting spectrum; it increases the inaccuracy depending on the excited region of the gradient pulse. This effect leads to appearing of intermediate signals in DOSY spectra. Moreover, exchange processes can have an effect on the accuracy of determination of self-diffusion coefficients. A classical way to eliminate the $J$-modulation of the spin echo is using the CPMG method (Carr-Purcell-Meiboom-Gill), ${ }^{[53]}$ in which the spin-echo sequence is applied with a short delay between pulses. Unfortunately, it requires high-power RF pulses which lead to sample heating and arising of convection which distorts the experiment results. In addition, short and intense pulses also facilitate cross-relaxation (in this case - nuclear Overhauser effect in rotating frame, ROE, unlike NOE in the STE experiments). Another method of suppressing $J$-modulation using quadrature $90^{\circ}$ pulses in the middle of the double spin echo period ${ }^{[47]}$ was presented in ${ }^{[54]}$; this approach is sometimes called "ideal spin echo".

In this paper, effect of exchange processes on accuracy of diffusion measurements performed by two mentioned methods is analyzed. Half-widths of the "diffusion spectrum" peaks were considered as the criterion of the accuracy. The diffusion spectra were obtained by projecting 2D DOSY spectra onto the indirect dimension (summation of 1D slices over a certain range of chemical shifts). Each of the peaks in these spectra corresponds to self-diffusion coefficients of the studied compounds of their structural elements.

2D DOSY spectra of the nickel complex of inverted 2-aza-5,10,15,20-tetraphenyl-21-carboporhyrin, obtained using STE (Figure 2) and CPMG (Figure 3) approaches, show that the complex experiences chemical exchange with the solvent which leads to broadening of the DOSY peaks. Thus, inaccuracy (standard deviation) for corresponding atom groups should be taken into account in quantitative analysis 
of DOSY. Moreover, the values obtained using different experimental techniques (STE and CPMG) may differ due to abovementioned factors. The difference between observed self-diffusion coefficients of the solvent and porphyrin may also vary in the presence of exchange. Hence, an internal diffusion standard should be used for quantitative measurements of diffusion, as it was shown for other systems. ${ }^{[55]}$

\section{D DOSY STE}

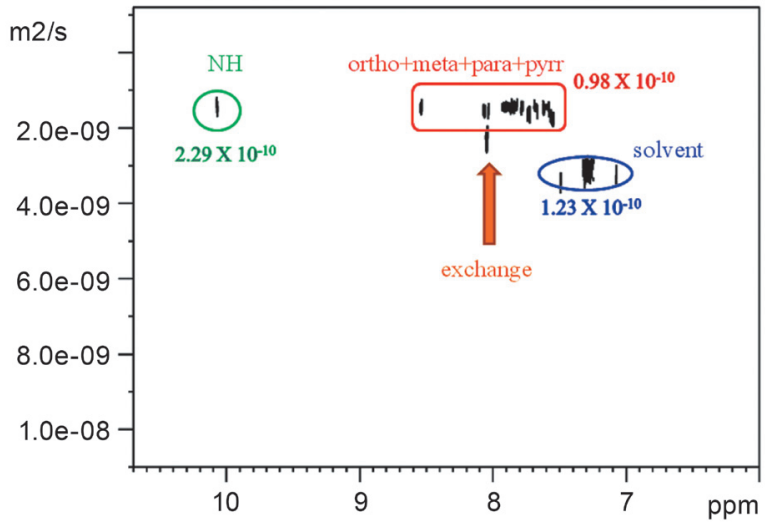

Figure 2. DOSY of the nickel complex of inverted 2-aza-5,10,15,20-tetraphenyl-21-carboporhyrin, obtained using STE. Numbers represent the inaccuracies in the self-diffusion coefficients $\left(\mathrm{m}^{2} / \mathrm{s}\right)$.

\section{D DOSY CPMG}

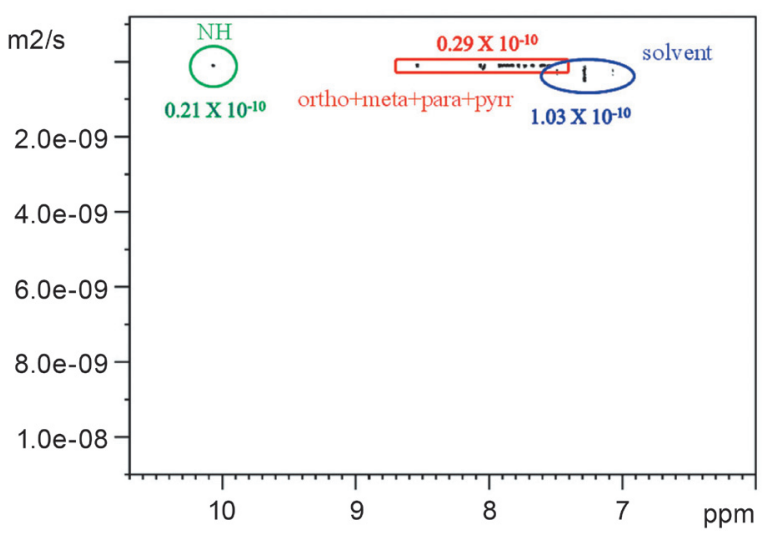

Figure 3. DOSY of the porphyrin-nickel complex, obtained using CPMG. Numbers represent the inaccuracies $\Delta D\left(\mathrm{~m}^{2} / \mathrm{s}\right)$.

To reveal the effect of exchange, standard deviations of the self-diffusion coefficients obtained for the characteristic groups of porphyrin which are subject to exchange (NH group) and do not experience it (phenyl and pyrrole ring protons) were analyzed.

The STE-based method gave the value of $\Delta D=0.98 \cdot 10^{-10} \mathrm{~m}^{2} / \mathrm{s}$ for groups not involved in chemical exchange, which is three time larger than it was in CPMGbased measurements $\left(0.29 \cdot 10^{-10} \mathrm{~m}^{2} / \mathrm{s}\right)$. For the groups subject to exchange, the inaccuracy in the first case was an order of magnitude larger than in the second method $\left(2.29 \cdot 10^{-10}\right.$ and $0.21 \cdot 10^{-10}$, respectively). Note also that the standard deviation characterizing the solvent's diffusion rate changes insignificantly. Moreover, an artifact exchange peak appears (shown by an orange arrow in Figure 2). Figures 4 and 5 show clearly these differences in the DOSY projection spectra obtained for characteristic resonance frequencies of amide protons (Figure 4) and protons of the porphyrin core (Figure 5). Evidently, the STE-type experiment gives peaks resembling Gaussian line for both $\mathrm{NH}$ and nonexchanging protons, while the CPMG-based method gives a narrow line with a shape close to Lorentzian one.

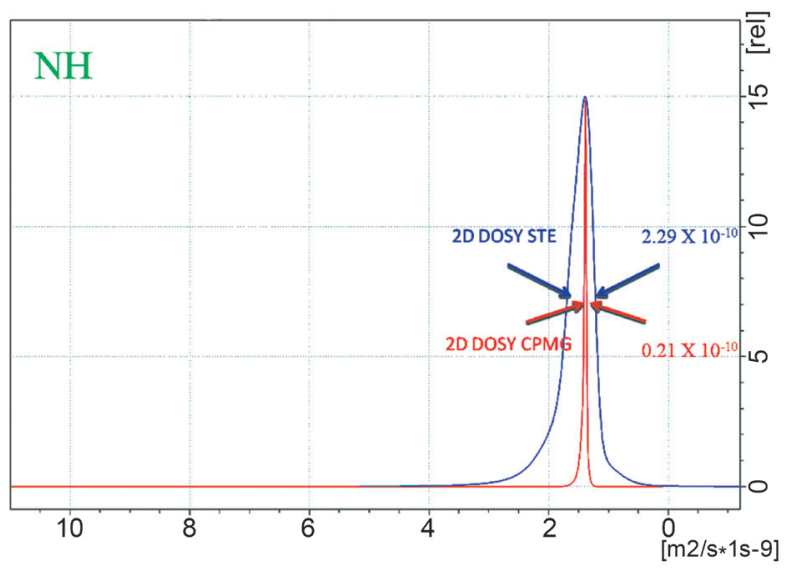

Figure 4. Projections of the STE-based (blue line) and CPMG-based (red line) 2D DOSY spectra of the nickelporphyrin complex for the $\mathrm{NH}$ group.

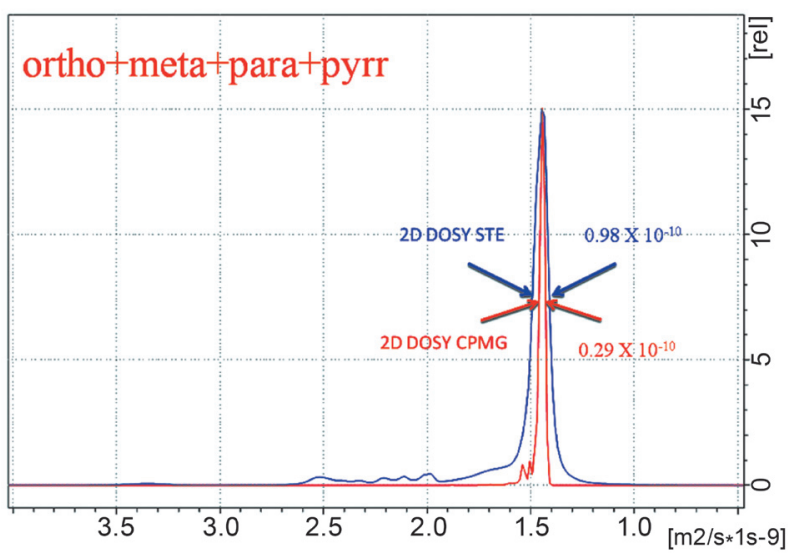

Figure 5. Projections of the STE-based (blue line) and CPMG-based (red line) 2D DOSY spectra of the nickel complex of inverted 2-aza-5,10,15,20-tetraphenyl-21carboporhyrin for the ortho-, meta-, and para-protons of the phenyl rings and protons of the pyrrole rings.

Thus, not only $J$-modulation but also exchange processes in the studied system should be considered in quantitative analysis of complex formation. At the same time, it is not always possible to use the solvent as the internal diffusion standard, and some other compound should be added for this purpose. Otherwise, analysis of the self-diffusion coefficients can lead to erroneous conclusions about the molecular-level processes. Proposed method of estimating the inaccuracies in self-diffusion coefficients may be used for various organic 
molecules. CPMG-based DOSY technique allows conducting quantitative description of the behavior of the studied system in different states (temperature, concentration, etc.).

Acknowledgments. I thank Dr. Olga V. Maltceva (ISC RAS) for her skilful technical assistance in preparation of NMR samples and the synthesis and supply with porhyrin complexes. Prof. Nugzar Zh. Mamardashvili (ISC RAS) and Prof. Michael G. Kiselev (ISC RAS) are appreciated for the very helpful discussions of the preliminary version of the manuscript. The work was supported by the Russian Foundation for Basic Research (projects no. 17-03-00459, 16-53-150007), grant of the President of the Russian Federation for support of young researchers - candidates of sciences MK-9046.2016.3, by the subsidy of the Russian Government to support the Program of Competitive Growth of Kazan Federal University among World's Leading Academic Centers.

\section{References}

1. Khodov I.A., Nikiforov M.Y., Alper G.A., Blokhin D.S., Efimov S.V., Klochkov V.V., Georgi N. J. Mol. Struct. 2013, $1035,358-362$.

2. Khodov I.A., Efimov S.V., Klochkov V.V., Alper G.A., Batista de Carvalho L.A.E. Eur. J. Pharm. Sci. 2014, 65C, 65-73.

3. Khodov I.A., Efimov S.V., Klochkov V.V., Batista de Carvalho L.A.E., Kiselev M.G. J. Mol. Struct. 2016, 1106, 373-381.

4. Khodov I.A., Efimov S.V., Nikiforov M.Y., Klochkov V.V., Georgi N. J. Pharm. Sci. 2014, 103, 392-394.

5. Kalmykov P.A., Khodov I.A., Klochkov V.V., Klyuev M.V. Russ. Chem. Bull. 2017, 66, 70-75.

6. Efimov S., Zgadzay Y., Klochkov V. Appl. Magn. Reson. 2014, $45,1225-1235$.

7. Efimov S.V., Karataeva F.K., Aganov A.V., Berger S., Klochkov V.V. J. Mol. Struct. 2013, 1036, 298-304.

8. Bikmullin A.G., Alimova F.K., Aganov A.V., Klochkov V.V., Usachev K.S. Res. J. Pharm. Biol. Chem. Sci. 2015, 6, 25-31.

9. Usachev K.S., Efimov S.V., Kolosova O.A., Klochkova E.A., Aganov A.V., Klochkov V.V. J. Biomol. NMR 2015, 62, 71-79.

10. Usachev K.S., Filippov A.V., Khairutdinov B.I., Antzutkin O.N., Klochkov V.V. J. Mol. Struct. 2014, 1076, 518-523.

11. Ksenofontov A.A., Guseva G.B., Antina E.V., Khodov I.A., Vyugin A.I. Sens. Actuators, B Chem. 2017, 251, 858-868.

12. Maltceva O., Mamardashvili G., Khodov I., Lazovskiy D., Khodova V., Krest'yaninov M., Mamardashvili N., Dehaen W. Supramol. Chem. 2017, 29, 360-369.

13. Khodov I.A., Alper G.A., Mamardashvili G.M., Mamardashvili N.Z. J. Mol. Struct. 2015, 1099, 174-180.

14. Bichan N.G., Tyulyaeva E.Y., Khodov I.A., Lomova T.N. J. Mol. Struct. 2014, 1061, 82-89.

15. Khodov I.A., Nikiforov M.Y., Alper G.A., Mamardashvili G.M., Mamardashvili N.Z., Koifman O.I. J. Mol. Struct. 2014, 1081, 426-430.

16. Ballester P., Claudel M., Durot S., Kocher L., Schoepff L., Heitz V. Chem. Eur. J. 2015, 21, 15339-15348.

17. Malyasova A.S., Kokareva E.A., Tarakanov P.A., Aleksandriiskii V.V., Khelevina O.G., Koifman O.I. Russ. J. Org. Chem. 2014, 49, 1812-1818.

18. Marchand G., Roy H., Mendive-Tapia D., Jacquemin D. Phys. Chem. Chem. Phys. 2015, 17, 5290-5297.

19. Paul A.K., Karunakaran S.C., Joseph J., Ramaiah D. Photochem. Photobiol. 2015, 91, 1348-1355.

20. Renney C.M., Fukuhara G., Inoue Y., Davis A.P. Chem. Commun. 2015, 51, 9551-9554.
21. Watarai H., Kurahashi Y. Anal. Chem. 2016, 88, 4619-4623.

22. Xie J., Chen X., Huang Z., Zuo T. J. Mol. Model. 2015, 21, 140.

23. Yang J., Wang Z., Hu K., Li Y., Feng J., Shi J., Gu J. ACS Appl. Mater. Interfaces 2015, 7, 11956-11964.

24. Zhao T., Wang Y.-L., Zhu L.-N., Huo Y.-F., Wang Y.-J., Kong D.-M. RSC Adv. 2015, 5, 47709-47717.

25. Babailov S.P. Macroheterocycles 2010, 3, 218-221.

26. Brotherhood P.R., Luck I.J., Crossley M.J. Magn. Reson. Chem. 2009, 47, 257-262.

27. Volov A.N., Zamilatskov I.A., Mikhel I.S., Erzina D.R., Ponomarev G.V., Koifman O.I., Tsivadze A.Y. Macroheterocycles 2014, 7, 256-261.

28. Stolypko A.L., Belykh D.V. Macroheterocycles 2015, 8, 389-393.

29. Belykh D.V., Stolypko A.L. Macroheterocycles 2017, 10, 51-56.

30. Stolypko A.L., Belykh D.V. Startseva O.M. Macroheterocycles 2015, 8, 47-49.

31. Durot S., Taesch J., Heitz V. Chem. Rev. 2014, 114, 8542-8578.

32. Oliva A.I., Gómez K., González G., Ballester P. New J. Chem. 2008, 32, 2159-2163.

33. Watanabe H., Kamatani Y., Tamiaki H. Chem. - An Asian J. 2017, 12, 759-767.

34. Chiba Y., Liu M., Tachibana Y., Fujihara T., Tsuji Y., Terao J. Chem. - An Asian J. 2017, 12, 1900-1904.

35. Ikawa Y., Takeda M., Suzuki M., Osuka A., Furuta H. Chem. Commun. 2010, 46, 5689-5691.

36. Ishizuka T., Yamasaki H., Osuka A., Furuta H. Tetrahedron 2007, 63, 5137-5147.

37. Krasnikov S.A., Sergeeva N.N., Brzhezinskaya M.M., Preobrajenski A.B., Sergeeva Y.N., Vinogradov N., Cafolla A.A., Senge M.O., Vinogradov A.S. J. Phys. Condens. Matter 2008, 20, 235207.

38. Thomas A.P., Saneesh Babu P.S., Asha Nair S., Ramakrishnan S., Ramaiah D., Chandrashekar T.K., Srinivasan A., Radhakrishna Pillai M. J. Med. Chem. 2012, 55, 5110-5120.

39. Xie Y.S., Yamaguchi K., Toganoh M., Uno H., Suzuki M., Mori S., Saito S., Osuka A., Furuta H. Angew. Chem. Int. Ed. 2009, 48, 5496-5499.

40. Zhu X., Wong W.-K., Lo W.-K., Wong W.-Y. Chem. Commun. 2005, 1022-1024.

41. Harvey J.D., Ziegler C.J. Chem. Commun. (Camb.) 2002, 2, 1942-1943.

42. Khodov I.A., Maltceva O.V., Klochkov V.V., Koifman O.I., Mamardashvili N.Z. New J. Chem. 2017, 41, 7932-7937.

43. Srinivasan A., Furuta H., Osuka A. Chem. Commun. 2001, 1666-1667.

44. Furuta H., Asano T., Ogawa T. J. Am. Chem. Soc. 1994, 116, 767-768.

45. Furuta H., Maeda H., Osuka A. J. Org. Chem. 2001, 66, 85638572.

46. Ishikawa Y., Yoshida I., Akaiwa K., Koguchi E., Sasaki T., Furuta H. Chem. Lett. 1997, 26, 453-454.

47. Aguilar J.A., Adams R.W., Nilsson M., Morris G.A. J. Magn. Reson. 2014, 238, 16-19.

48. Pelta M.D., Morris G.A., Stchedroff M.J., Hammond S.J. Magn. Reson. Chem. 2002, 40, S147-S152.

49. Botana A., Aguilar J.A., Nilsson M., Morris G.A. J. Magn. Reson. 2011, 208, 270-278.

50. Johnson C.S. J. Magn. Reson. Ser. A 1993, 102, 214-218.

51. Cabrita E.J., Berger S., Bräuer P., Kärger J. J. Magn. Reson. 2002, 157, 124-131.

52. Chen A., Shapiro M. J. Am. Chem. Soc. 1999, 121, 5338-5339.

53. Zhang X., Li C.-G., Ye C.-H., Liu M.-L. Anal. Chem. 2001, 73, 3528-3534.

54. Aguilar J.A., Nilsson M., Bodenhausen G., Morris G.A. Chem. Commun. 2012, 48, 811-813.

55. Cabrita E.J., Berger S. Magn. Reson. Chem. 2002, 40, S122S127. 